\title{
THE LATE RESULTS OF THE CONSERVATION OF THE APICAL SEGMENT OF THE LOWER LOBE IN RESECTIONS FOR BRONCHIECTASIS
}

\author{
BY \\ E. HOFFMAN \\ From the Regional Thoracic Surgery Centre, Shotley Bridge Hospital, Newcastle-upon-Tyne
}

(RECEIVED FOR PUBLICATION DECEMBER 24, 1954)

In a number of cases where the presumably healthy apical segment of the lower lobe was preserved in resections for bronchiectasis a high incidence of persistent post-operative atelectasis and bronchiectasis was found. Because of this a series of cases was reviewed to find out whether conservation of the apical segment is likely to produce satisfactory results. In some of the cases the basal segments alone were removed, in others the basal segments together with other segments or lobes. As the post-operative follow-up for a period of six months gave very disappointing results, it was decided to reassess these cases after a period of at least two years after operation.

Fifty-one patients in whom the apical segment was preserved were considered. In four of these the basal segmental resection was bilateral. These were compared with a group of 51 successive patients who had a resection of the lower lobe and lingula and another group of 51 patients who had had a lower lobectomy. All operations were carried out for bronchiectasis and were performed at the Shotley Bridge Regional Chest Surgery Centre between June, 1948, and April, 1952. The resections were done by various members of the staff and some by trainee surgeons. Bronchograms were done pre-operatively and post-operatively in all cases.

The apical segment was conserved mainly in cases with extensive bronchiectasis. Forty-one out of 51 patients had bilateral disease; in 22 bronchiectasis was present in four or five lobes.

Results in the early post-operative months were poor. In the absence of post-operative complications bronchograms were usually done after one to two months and in all cases within six months from operation. These bronchograms showed an entirely satisfactory residual apical segment in only 27 cases.
Bronchial dilatations were present in nine cases and in $\mathbf{1 5}$ the bronchi of this segment could not be filled even after repeated attempts; all these apical segments showed partial or total atelectasis.

In the few published results on this subject the experience of others has been similar to ours. Kergin (1950) reviewed 11 cases and had only five good results. Glennie (1952) analysed 30 cases, in 19 of which post-operative bronchographic appearances were satisfactory, while in 11 cases the residual apical segments were collapsed or bronchiectatic. Mathey and Toussaint (1950) prefer a lower lobectomy to conservation of the apical segment.

Persistent atelectasis of the residual apical segment is the complication most commoniy found in the post-operative period. This is probably due to aspiration of bronchial secretions in the majority of cases. Conditions which favour collapse include displacement of the segment, prolonged bronchial air leaks, and empyema. In one of our cases surgical narrowing was confirmed at bronchoscopy as the cause of atelectasis. In another case the apical segmental artery was injured during its dissection, and, although the tear was meticulously sutured and there seemed satisfactory pulsation, this segment remained permanently collapsed. Overholt and Woods (1950) described a case of basal segmental resection where the residual apical segment was found at necropsy to be engorged with blood. They suggested that this might have been caused by obstruction of the venous drainage from the apical segment due to manipulation of the lobe during its dissection. We have had no similar experience.

An attempt was made to correlate the high incidence of unsatisfactory post-operative results with pre-operative findings. The history of the 


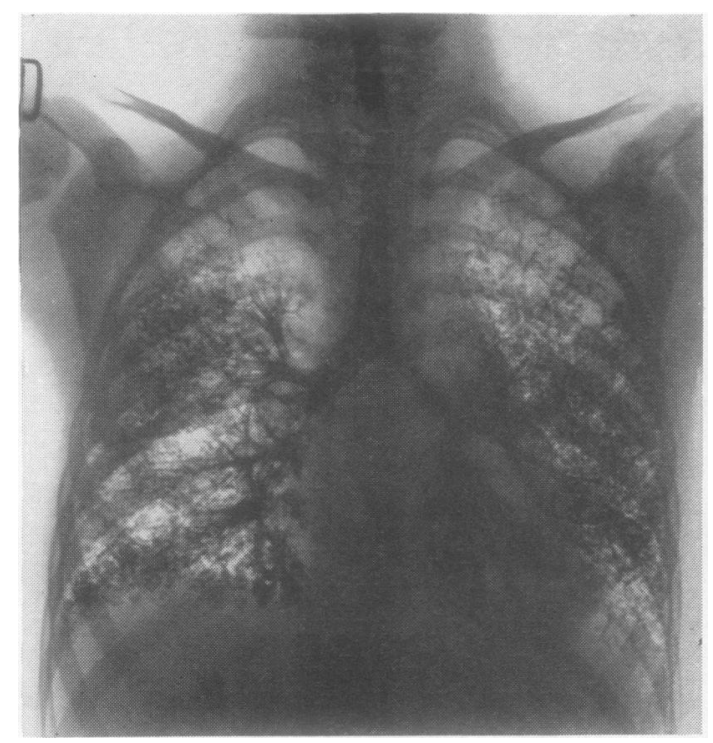

FIG. 1a.-Pre-operative bronchogram of a toy aged 8 with bronchiectasis of the right basal segments and of the left lower lobe.

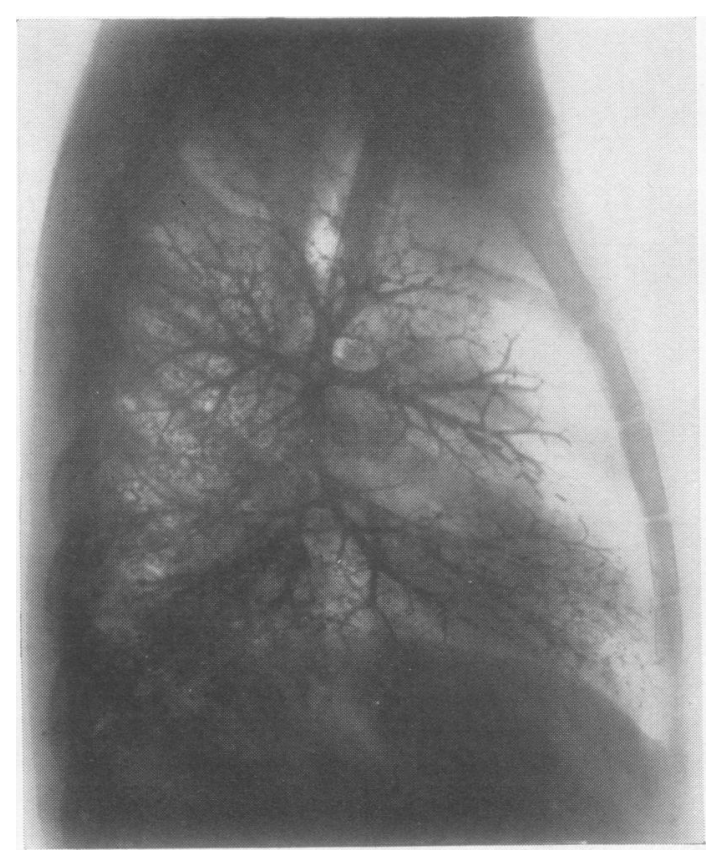

FIG. 1b.-Pre-operative right lateral view illustrating the healthy apical segment of the lower lobe. Bilateral resection was carried uut.
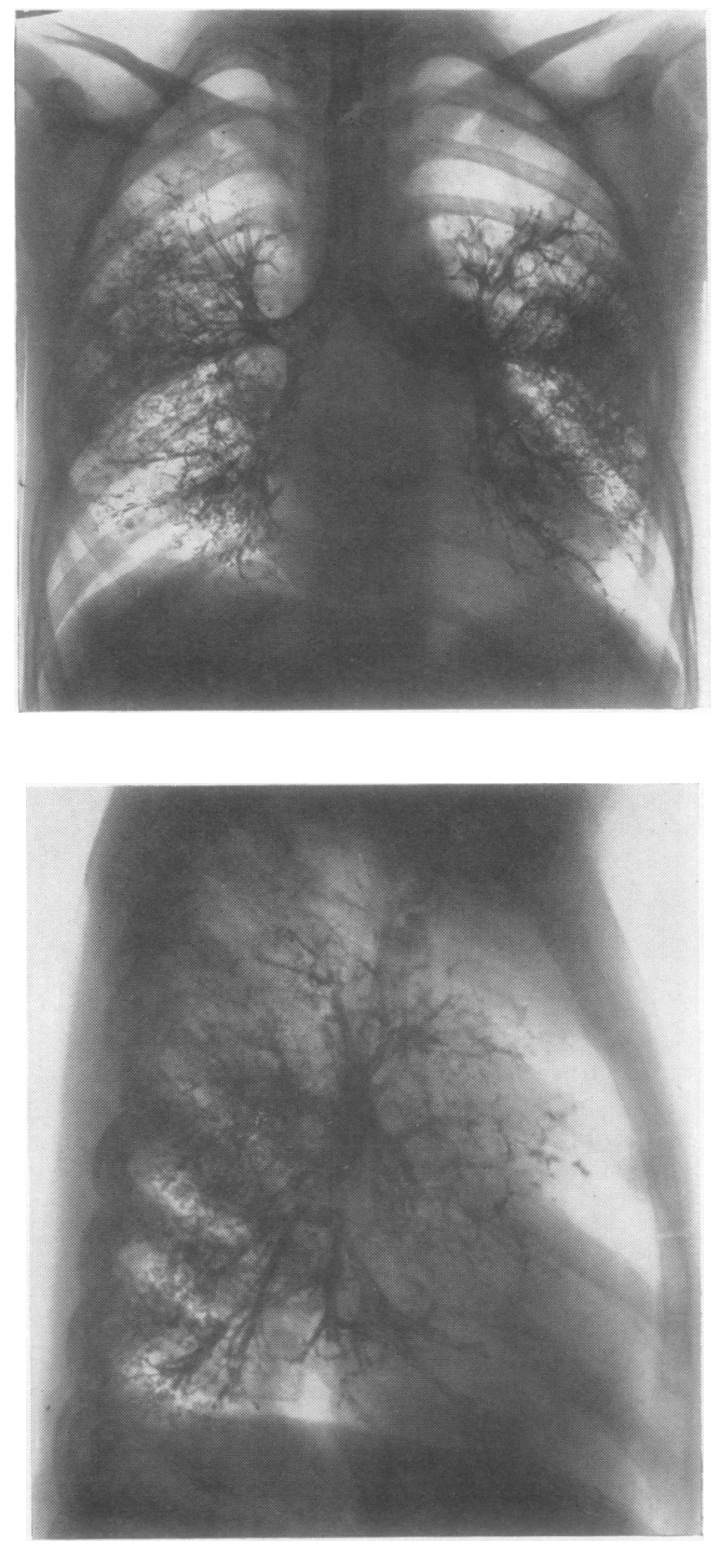

Figs. $1 c$ and d.-Post-operative bronchograms showing a satisfactory residual apical segment. These bronchograms were done three months after resection of the right basal segments. The lef side had been operated on previously. 

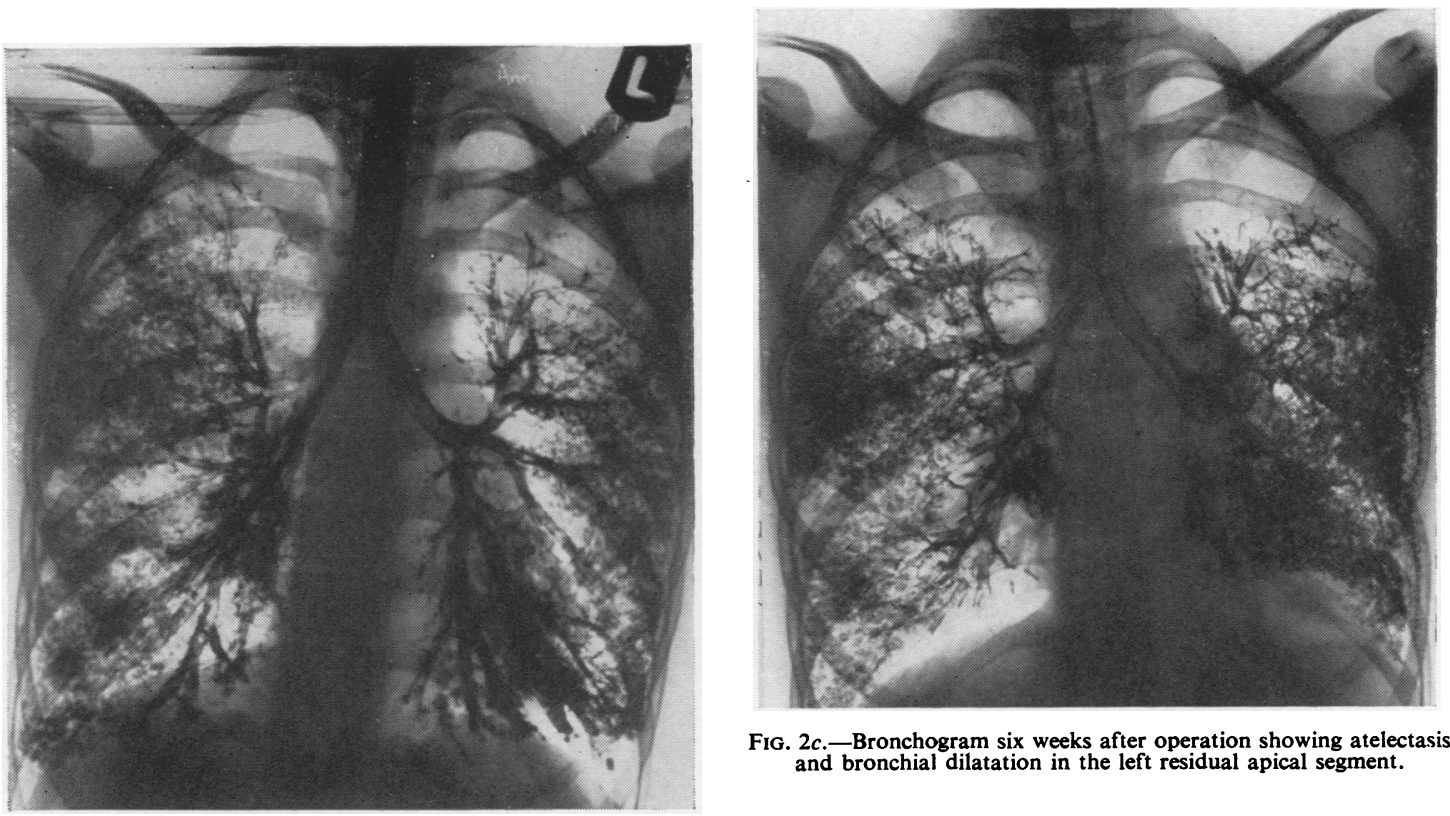

FIG. 2c.-Bronchogram six weeks after operation showing atelectasis and bronchial dilatation in the left residual apical segment.

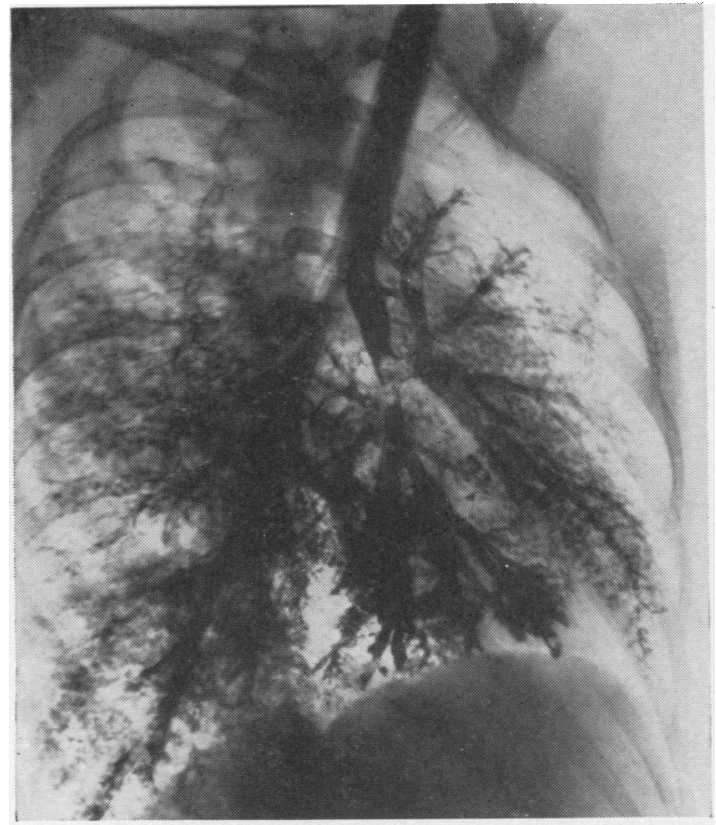

Figs. $2 a$ and $b$.-Pre-operative postero-anterior and oblique views of a girl aged 11 with bilateral bronchiectasis. The right middle lobe and anterior segment of the right upper lobe are involved, also one segment of the lingula and the left basal segments. The apical segment of the left lower lobe appears healthy.

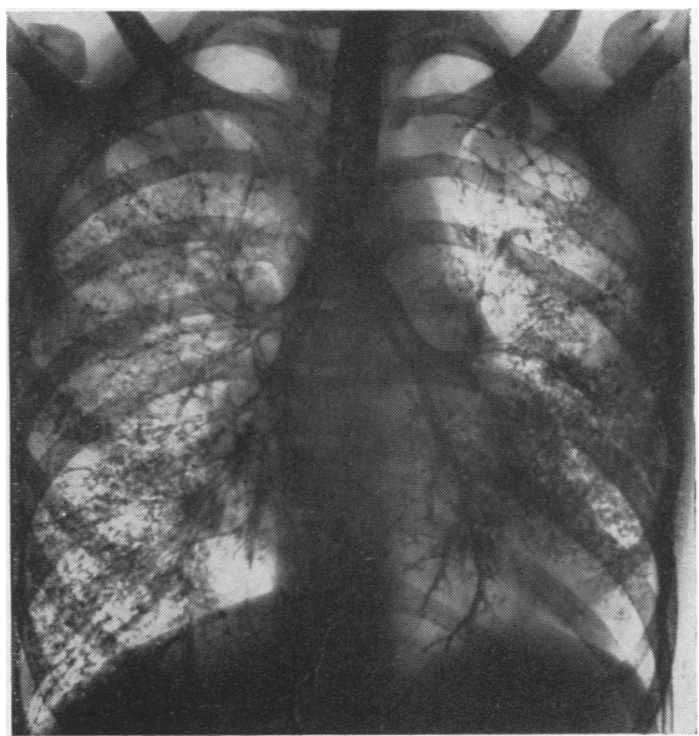

FIG. 2d.-The bronchographic appearances after a year show re-aeration and a return to a normal bronchial pattern in the retained apical segment. 
disease, the age of the patients, the symptomatology and clinical findings (including a thorough E.N.T. examination and bacteriological investigation of the upper respiratory tract) did not provide any common factor to account for these results.

From our series it appears that the incidence of bronchopleural fistula and empyema is similar in different types of segmental resection for bronchiectasis (Table I).

TABLE I

INCIDENCE OF BRONCHOPLEURAL FISTULA AND EMPYEMA IN THREE GROUPS OF 51 PATIENTS

\begin{tabular}{l|c|c|c}
\hline & \multicolumn{3}{|c}{ Results (No. of Cases) } \\
\cline { 2 - 4 } & $\begin{array}{c}\text { Group A: } \\
\text { Conserved } \\
\text { Apical } \\
\text { Segment }\end{array}$ & $\begin{array}{c}\text { Group B: } \\
\text { Resection } \\
\text { of Lower } \\
\text { Lobe and } \\
\text { Lingula }\end{array}$ & $\begin{array}{c}\text { Group C: } \\
\text { Resection } \\
\text { of } \\
\text { Lower } \\
\text { Lobe }\end{array}$ \\
\hline $\begin{array}{c}\text { No post-operative complications } \\
\text { Bronchopleural fistula for 2 to } \\
\text { 20 days }\end{array}$ & 21 & 33 & 45 \\
$\begin{array}{c}\text { Empyema for 3 to 5 months } \\
\text { Emp }\end{array}$ & 8 & 11 & 1 \\
\hline
\end{tabular}

But the presence of these complications in basal segmental resection is more commonly associated with atelectasis of the residual apical segment (Table II).

\section{TABLE II}

CORRELATION OF RESULTS OF BASAL SEGMENTAL RESECTION WITH INCIDENCE OF BRONCHOPLEURAL FISTULA AND EMPYEMA

\begin{tabular}{l|c|c}
\hline & \multicolumn{2}{|c}{ Results (No. of Cases) } \\
\cline { 2 - 3 } & Good & $\begin{array}{c}\text { Atelectasis } \\
\text { of Residual } \\
\text { Apical Segment }\end{array}$ \\
\hline $\begin{array}{l}\text { No post-operative complications .. } \\
\text { Pneumonia in opposite lung } \ldots\end{array}$ & 21 & 12 \\
Bronchopleural fistula 2 to 20 days & 2 & 1 \\
Empyema for 3 to 5 months & 4 & 5 \\
\hline
\end{tabular}

In extensive disease, particularly in bilateral bronchiectasis, preservation of a maximum volume of healthy lung is of great importance. The apical segment is not a common site for bronchiectasis. Whitwell (1952) examined 114 lower lobe specimens removed for bronchiectasis and found the apical segment unaffected in 78 cases. It is also well known that atelectatic lung segments or lobes can re-aerate without any loss of function after months and even years, provided that the bronchi and surrounding lung parenchyma are not permanently damaged. It was therefore decided to carry out a late follow-up of cases which had had a poor result in the early post-operative months.

Atelectasis is almost invariably accompanied by bronchiectasis. It is important, especially from a surgical point of view, to distinguish between cases $\stackrel{\overrightarrow{\vec{S}}}{\overrightarrow{7}}$ of reversible and irreversible bronchiectasis. It is $\overline{0}$ difficult to know which of these segments will $\overline{0}$ re-aerate, particularly in the absence of gross $\frac{\bar{m}}{5}$ symptoms of bronchiectasis. Observation for $a \stackrel{\mathbb{Q}}{\propto}$ prolonged period of time alone can give an answer. Only those segments will remain permanently collapsed where (1) infection has led to destruction. of the bronchi and lung parenchyma with fibrosis, $\overrightarrow{\vec{\omega}}$ (2) lung tissue has been prevented from re-expansion by a thick pleural cortex as a result of pleural $\overrightarrow{\vec{x}}$ infection, or (3) the bronchial orifice is permanently narrowed.

Patients with segments which showed permanent $\stackrel{N}{\vec{\omega}}$ post-operative atelectasis have been followed up $\vec{v}$ for a period of two to six years. Not all the $?$ patients in the late follow-up had bronchographic examinations; in some postero-anterior and lateral $c$ films were accepted for comparison. Of the $24 \stackrel{\mathrm{D}}{2}$ apical segments which had atelectasis of varying $\vec{\theta}$ degree, 18 re-aerated fully with a good clinical of result. The exact time of re-aeration could not be determined, but it was established one to six years after operation. Where a bronchogram was done re-aeration was found to be accompanied by a return from bronchiectasis to a normal bronchial tree (Figs. $2 a, b, c, d$ ). Of the six remaining patients, four had residual apical segments which remained permanently collapsed ; three of these are symptomless and one had to have the residual apical segment removed four years after the original operation because of persistent symptoms of bronchiectasis; one patient could not be traced and one died of a respiratory flare-up.

TABLE III

RESULTS COMPARED OF BASAL SEGMENTAL RESECTION, LOWER LOBE AND LINGULA RESECTION, AND LOWER

\begin{tabular}{|c|c|c|c|}
\hline & \multicolumn{3}{|c|}{ Results (No. of Cases) } \\
\hline & Good & $\begin{array}{c}\text { Atelectasis } \\
\text { of } \\
\text { Residual } \\
\text { Apical } \\
\text { Segment }\end{array} \mid$ & $\begin{array}{c}\text { Bronchiec } \\
\text { tasis } \\
\text { of } \\
\text { Residual } \\
\text { Lung }\end{array}$ \\
\hline $\begin{array}{l}\text { Basal segmental resection: } 1-6 \\
\text { months follow-up } \\
\text { Basal segmental resection: } \\
6 \text { years follow-up } \\
\text { Resection of the lower lote and } \\
\text { lingula } \\
\text { Resection of the lower lobe }\end{array}$ & $\begin{array}{l}27 \\
45 \\
48 \\
50\end{array}$ & $\begin{array}{r}24 \\
4\end{array}$ & $\begin{array}{l}0 \\
0 \\
3 \\
1\end{array}$ \\
\hline
\end{tabular}

The satisfactory result of basal segmental resection in 45 patients is as good as the results for other segmental resections and almost as good as those for lower lobectomy. 


\section{Discussion}

Resection of the basal segments with conservation of the apical segment of the lower lobe is a satisfactory procedure especially in widespread disease. In cases where bronchiectasis is localized to one or perhaps two lobes a lower lobectomy may be preferable because conservation of the apical segment has a higher rate of post-operative complications and the end-results are slightly less satisfactory. Where resection with conservation of the apical segment has been decided to be the operation of choice and this segment becomes atelectatic post-operatively, it is recommended that conservative treatment should be carried out for several years, especially in the absence of symptoms of bronchiectasis, because a large proportion of these lobes have been found to re-aerate.

\section{SUMmaRY}

A series of 51 patients with bronchiectasis has been investigated where the basal segments have been resected with conservation of the apical segment of the lower lobe.

An early follow-up to six months and a late follow-up from two to six years from operation has been carried out.

Early post-operative results showed a high incidence of atelectasis of the residual apical segment. This atelectasis has been found to be reversible, and the late follow-up showed endresults as good as those for other segmental resections for bronchiectasis.

I should like to thank Mr. George A. Mason, who stimulated my interest in this subject, Dr. Whately Davidson for his help in the interpretation of the radiographs, and colleagues at this clinic for their helpful criticisms.

\section{REFERENCES}

Glennie, J. (1952). Personal communication. Kergin, F. G. (1950). J. thorac. Surg., 19, 257.

Mathey, J., and Toussaint, J. (1950). Acta chir. belg., 49, 747 .

Overholt, R. H., and Woods, F. M. (1950). J. thorac. Surg., 19, 207. Whitwell, F. (1952). Thorax, 7, 213 